\title{
The Value and Identity of Business
}

\author{
Towards a Logical Framework of Business Value
}

Christopher S. Gifford

\begin{abstract}
This article is an exercise in the transposition of certain approaches in analytic philosophy to issues concerning business value and identity in business. We examine the notion of business value and several accounts of value that have been offered in the literature. Luciano Floridi's formal logical account of a business is introduced and applied as a first step towards a logical framework of business value. Peter Peverelli has claimed that Chinese business identity is accounted for in terms of competitors, administration levels, hierarchical structures, and those government agencies with jurisdiction over enterprises (viz. regulators). It is argued that this quadripartite method of identification cannot be fully generalized to all businesses in any geographical location since distinct businesses can exist which have the same competitors, administration levels, hierarchical structures, and governed by the same government agencies. In such a case the distinguishing features of the businesses are the job descriptions or duties of the employees. Hence job descriptions or duties play an important role in the identification of businesses. It turns out that the identification of business according to the job descriptions of employees has less in common with Peverelli's approach and more in common with Bang, Cleemann, and Drucker's notion of business value understood in terms of the technical and the social "as processes and as outputs of production".
\end{abstract}

Keywords-business value, business identity, logical modelling, digital busienss value, virtual business value

\section{Introduction}

What is business value? Something to be maximised, a pithy respondent may offer. Such a response captures the central crux of the notion of value as applied to business; everyone knows what should be done with it, yet we do not have a precise conception of what it is. It is tempting to provide a nihilistic diagnosis of the culprit for this lack of precision - the notion of business value is too general and too ambiguous to be adequately captured. That the notion of business value takes a primary and crucial role in business thinking only serves to compound the matter. Yet the establishment of extant frameworks used to model different varieties of business value tell in favour of a successful and suitable modelling of the notion in full generality.

What is business identity? This is an easier question than the one above. We can identify business value in a standard logical or philosophical way in the analytic philosophical tradition - by the properties of a business. The identity of business comes with a more obvious conception, free from generality and ambiguity in contrast to business value. We know what a firm is - if we want to find out more about a company we can research its CEO or managing director which can serve to distinguish the

\section{Christopher S. Gifford}

Royal Institute of Philosophy, University of Bristol UK company from other companies; if we want to find the share price of a company we can reach for the stock market price - and each company is adequately distinguished in this sense. Moreover, the digitisation of business has held no problem for potential customers to identify businesses online; a brand name and logo of a corporation displayed online suffices, just as their display has done before in the non-digital world before the internet.

In what follows we give examples of different varieties of business value that have been introduced in the business literature (in II) and give a treatment of value in the analytic philosophy tradition. In IIA we discuss the pertinence of business value in the digital or virtual sphere before introducing a framework given by Luciano Floridi (in [1]) as a first step to logically model business value in its full generality, which includes the ability to model business value in the digital or virtual sphere. In III we examine the notion of business identity and scrutinize Peter Peverelli's criteria for Chinese business identity and demonstrate that it is not generalizable to all businesses regardless of geographical location. IV connects the findings of business value with those of business identity. We argue here that identity and value are importantly linked by two key areas; by the job descriptions of employees and by the provision of business. For the former, we provide a counter-example to Peverelli's criteria. The latter is the first step forward in the provision of a logical method of an analysis of business value. Let us begin with an examination of value.

\section{Value}

The most central concept to business, aside of business itself, is that of value. Value can be created. Value can be destroyed. And for some (such as Peter Drucker), it is the corner stone of all business - the purpose of all business is to create value and to create it for the customers. This is reflected in management by objectives, a goal-orientated method designed to shore up business value from the managerial decision making process. Value is integral to entrepreneurship, which arises from the creation of a new way of value creation and grows by a constant addition of this value. The concept of value is also a linchpin in the connection between business and society; business contributes to society only in so far as society appreciates the value a business provides (with shared value becoming increasingly popular (see [2])).

A most obvious and straightforward measurement of value is in terms of profits or capital - a direct monetary quantization of value. Value understood as profit margin can be calculated by: value created - cost of creating value $=$ profit margin. And a stereotypical response to the question of how to maximize value is standardly that this is done by the maximization of profits. Another method for calculating business value is by a comparison between earnings, 
interest, and tax. The notion defined in this manner can depreciate and is subject to amortization. But, despite the ease of these methods, they fall short of capturing a full appreciation of what business value is (see, for example, [3]).

Value can come from a host of sources. One public valuation of a corporation is it share value, calculated by price multiplied by the number of shares outstanding (market capitalization). An extension of this conception of business value is in terms of shareholders - Shareholder Value Analysis (SVA) - which is calculated by dividing the estimated total net value of a company based on present and future cash-flows by the value of its shares. In risk calculation, an accurate estimation of expected value is crucial and is broken down into realized and expected value. But the quantitative approach of SVA or any other quantitative approach such as in risk is not exhaustive of the methods by which business value can be understood. Both these methods, while accurate for the kind of value they are intended to capture, fall short or incorporating a vital aspect of business value: the role of individuals.

R. Edward Freeman's stakeholder theory [4] is a move in the direction of the acknowledgement of the importance of individuals in business value. Stakeholder theory claims that firms ought to be managed to balance all the interests of the stakeholders. A substantial aspect of this is the prescriptive maximization of value for stakeholders.

A more pragmatic analysis has been offered by Adam Lindgreen [5]. Lindgreen proposes a theory of shareholder value creation which results in customer retention. The emphasis here is on relationship quality, broken down into the dimensions of trust in credibility, trust in benevolence, commitment, conflict, satisfaction, and social bonding (originally introduced by Roberts [6] and Roberts, Varki and Brodie [7]).

Michael Porter's ubiquitous value chain [8] (pp. 11-15) segments the primary activities of a business into inbound logistics, operations, outbound logistics, marketing \& sales, and service. Support activities of these primary activities consist of firm infrastructure, human resource management, technology development, and procurement. This model enables the identification of value in a specific area of business and enables the tracking of value so that it can be maintained or increased. In this fashion, different processes within a business in which value consists in can be identified in an input-output model of subsystems.

In addition to the above, there are also the corporate values that define the culture within a business and can serve as drivers. From the myriad non-exhaustive notions of value considered in the examples above, those displayed in Table 1 , and the highly general application of business value we can surmise that the general notion of business value is inherent in all these instances of value.

We make the distinction between value for and value from. Value for is a variety of value which is specifically identified in terms of who receives the value - for example, in some instances of value such as customer value, the value is received by customers. Value from is a variety of value identified in terms of the source of the value. For example, some of the value concepts listed in Table 1 have different sources.

TABLE I. A NON-EXHAUSTIVE LIST OF VARIETIES OF BUSINESS

\begin{tabular}{|c|c|c|c|}
\hline \multirow{2}{*}{$\begin{array}{c}\text { Value } \\
\text { Concepts }\end{array}$} & \multirow[b]{2}{*}{ Characterization } & & \\
\hline & & Value for & Value from \\
\hline $\begin{array}{l}\text { Corporate } \\
\text { Value(s) }\end{array}$ & $\begin{array}{l}\text { Values that drive } \\
\text { business }\end{array}$ & $\begin{array}{l}\text { Multiple/ } \\
\text { Variable }\end{array}$ & Corporation \\
\hline $\begin{array}{l}\text { Customer Value } \\
\text { (Customer } \\
\text { Value } \\
\text { Proposition } \\
(\text { CVP)) }\end{array}$ & $\begin{array}{l}\text { Benefits promised } \\
\text { to a customer }\end{array}$ & Customers & $\begin{array}{l}\text { Corporation } \\
\text { /employees }\end{array}$ \\
\hline $\begin{array}{l}\text { Channel Partner } \\
\text { Value }\end{array}$ & $\begin{array}{l}\text { Value added by } \\
\text { partners }\end{array}$ & A business & $\begin{array}{l}\text { Channel } \\
\text { partners }\end{array}$ \\
\hline $\begin{array}{l}\text { Employee } \\
\text { Value } \\
\text { (Emplyee Value } \\
\text { Proposition } \\
(\text { EVP)) }\end{array}$ & $\begin{array}{lr}\text { Benefits } & \text { and } \\
\text { rewards } & \text { for } \\
\text { emplyees } & \text { for } \\
\text { performance } & \end{array}$ & Employee & $\begin{array}{c}\text { Benefits and } \\
\text { Rewards }\end{array}$ \\
\hline $\begin{array}{l}\text { Managerial } \\
\text { Value }\end{array}$ & $\begin{array}{lr}\text { Portion } & \text { of } \\
\text { managerial } & \text { salary } \\
\text { assigned } & \text { to } \\
\text { product }^{\mathrm{b}} & \\
\end{array}$ & Managers & Salary \\
\hline $\begin{array}{l}\text { Societal/Social } \\
\text { Value }\end{array}$ & $\begin{array}{l}\text { Positive } \\
\text { contribution to } \\
\text { society }\end{array}$ & Society & A business \\
\hline $\begin{array}{l}\text { Supplier Value } \\
\text { (Value Stream } \\
\text { Analysis } \\
\text { (VSA)) }\end{array}$ & $\begin{array}{lr}\text { Several; } & \text { e.g. } \\
\text { transaction } & \text { value, } \\
\text { generative } & \text { value, } \\
\text { etc... } & \end{array}$ & Customers & Suppliers \\
\hline
\end{tabular}

A cause and effect analysis underpins the value for and value from distinction. Value for concerns the effect of the value - whether the consequence of the provision of value is that it is possessed by, for example, an employee or by society. Value from concerns the cause of the value - the source - whether it is, for example, caused by an increase in reward or by a business itself.

In the analytic tradition of philosophy, value theory offers a bipartite characterization of value: intrinsic value and extrinsic value and this distinction plays a part in the analysis of business value. Intrinsic value applies to things which are good solely in virtue of themselves, where intrinsic is understood as solely concerned with that object (e.g. an intrinsic duplicate is one which is exactly the same as another object in terms of all its internal properties). Extrinsic value applies to things which are good due to their relation to other things and so is related to other objects. The concept of value can then be whittled down to what is good or bad and comparatives and superlatives of these concepts can applied accordingly (e.g. 'societal value is better than channel partner value'). Let us now consider business value in the digital or virtual sphere.

\section{A. Value in the Digital/Virtual Sphere}

Times have changed and continue to change. The role of the digitalisation or virtualisation of business has had huge ramifications on the workplace and revolutionised the role of business value (see [13] p. 14). For example, there is a 
positive and significant relationship between firm web visibility and shareholder value [14], where web visibility is the extent to which a user is likely to encounter a reference to a web site (such as a brand name or logo) in his/her web/online environment.

Modern technological advances have also added to the complexity of business value by the supplementation of the virtual dimension of value. For example, the cloud furnishes the potential to expand customer value, and the potential for cost reduction for business in tandem with an increase in agility; cloud-based value can be created by a service provider due to the increased competency a service provider offers and through an enhancement of the availability of data (see [15], pp.78-79), where agility is understood as business flexibility. Hence digital or virtual business value, understood as value from digital or virtual sources. That virtual or digital environments are so integral to unicorns (or, rather, dedacorns) such as Uber, Snapchat, and Airbnb is no coincidence. Use of the knowledgeeconomy and digital tools to increase business value is now standard.

The objective of increasing business value for a firm is an important diver in the digital or virtual sphere which can give the edge over competitors, just as long as the value offered is distinctive from competitors. For example, consider AOL and Google in 2013; AOL offered the value of instant messengers and chat rooms whereas the latter offered the value inherent in its search engine (see [16]). The success of Google over AOL is a direct result of the value inherent in its search engine.

\section{B. A Model for Business Value}

The highly general nature of the concept of business value makes the provision of a suitable rigorous systemization remote. However, a recent model of moral action has been offered by Floridi ([1], p.103) in which moral action is analysed as a dynamic system comprising of a combination of seven components. The components are:

a) The agent

b) The customer

c) The interactions between the agent and the customer

d) The agent's general frame of information

e) The factual information concerning the situation insofar as it is at least partly available to the agent

f) The general environment in which the agent and customer are located, and

g) The species situation in which the interaction occurs. ${ }^{1}$

Although this analysis has been used to model moral action, it turns out that it is also suitable for a model of business value and is sufficiently general to be applied to all instances of business value. Floridi provides the following two definitions:

\footnotetext{
$\left.{ }^{1} \mathrm{~b}\right), \mathrm{c}$ ), and f) has been altered from 'patient' in the original to 'customer'.
}

Business $($ agent $)=_{\text {def. }}$ the provider of goods or services to customers

Business $($ activity $)=_{\text {def. }}$ the provision of goods or services to customers.

From a)-g) we can provide the following application of predicates:

$$
\begin{aligned}
& A(x)=x \text { is an agent } \\
& B(x)=x \text { is a business } \\
& C(z)=z \text { is a customer } \\
& D(y)=y \text { is a (deliverable) good or service } \\
& P(x, y, z)=x \text { provides } y \text { to } z
\end{aligned}
$$

From which we get:

$$
\forall x(B(x) \equiv(A(x) \& \exists y \exists z D(y) \& C(z) \& P(x, y, z)))
$$

which can be understood as: $x$ counts as a business if and only if $x$ is an agent and $y$ is a good or service and $z$ is a customer, then $x$ provides $y$ to $z$. ([1], p.280.)

(3) offers a definition of a business. Moreover, it identifies the process by which business value is transmitted - through the provision relation. This account can be used to capture the general sense of value across the different instances of value we have noted above, since common to all are: an agent, a business, a customer, a (deliverable) good or service, and the provision relation. The account is also suitable for capturing digital or virtual value, since the provision can be digital or virtual provision (via digital tools). In addition, the value for and value from distinction is represented; in any instance of the provision relation $P(x, y, z)$, the value is either from $x$ (the agent (whose actions cause the value)) or $y$ (the good or service) and for $z$ (the customer (whose actions are effects of the value)). We note that when value is rendered with the provision relation, value is always extrinsic since it necessitates the provision relation which holds of other objects (viz. the goods or services and customer are included in this extrinsic value).

If we adopt the definition offered in (3), the identity of a business is parasitic upon the identities of the relevant agent, customer, and goods/service. One traditional formal logical method of identifying relations - such as the provision relation - is by the objects of which the relation holds. Hence, instances of provision depends upon which agents, customers, and good/services are taken into account. Let us now consider the notion of business identity.

\section{Business Identity}

Peter Peverelli ([17], pp.216-231) has claimed that Chinese corporate identity can be given in terms of the quadripartite method of:

- Competitors

- Administration levels 
- Hierarchical Structures

- Government agencies with jurisdiction over enterprises (viz. regulators).

Let us define a competitor and a hierarchical structure as follows:

$a$ is a competitor (organization) of $b$ (organization) $=_{\text {def. }} a$ and $b$ have a shared vision, offer a similar product or service, have shared goals and aims, and have goods or services which can be provided to the same customers.

a hierarchical structure $=_{\text {def. }}$ the roles or positions filled by employees and the corporate or organizational relations which hold between the roles or positions.

(5) can be supplemented using the standard mathematical characterization of a hierarchy, where the relations are strict partial orders; where a relation $R$ is a strict partial order when it is i) irreflexive, ii) asymmetric, and iii) transitive. That is, i) no hierarchical relation can hold between a role or position and that role or position, ii) if a hierarchical relation holds between a first role or position and a second role or position then that hierarchical relation does not hold between the second role or position and the first role or position. And iii) if a hierarchical relation holds between a first role or position and a second role or position and holds between that second role or position and a third role or position, then the hierarchical relation holds between the first role or position and the third role or position. From (5) we can define administration levels:

an administration level $=_{\text {def. }}$ the administrative roles or positions filled by employees and the administrative relations which hold between the roles or positions

and regulators can simply be defined in like fashion to Peverelli:

a regulator $=_{\text {def. }}$ a government agency with jurisdictions over enterprises.

Peverelli's definition accords with the standard analytic definition of identity. Two laws that govern identity in analytic philosophy are:

(PIIi) If a thing $=\mathrm{a}$ thing then all properties (attributes) of the former share all properties (attributes) of the latter.

(PIIii) If all properties (attributes) of a thing are shared with another thing then the former thing $=$ the latter thing. ((PIIii) is more controversial than (PIIi))

For example, consider the CEO of Virgin International and Richard Branson. Applying (PIIii), consider of all of the properties of the CEO of Virgin International and all the properties of Richard Branson. The properties are the same. The CEO of Virgin International and Richard Branson share all of their properties. Hence the CEO of Virgin International $=$ Richard Branson.
(PIIi) and (PIIii) are extremely general in that they take in to account all properties. In analytic philosophy, there are restrictions made to the kinds of properties used in (PIIi) and (PIIii) in order to make them less general and more informative (for example, sometimes intrinsic and extrinsic properties are invoked and possible properties are excluded).

Peverelli's criteria for Chinese corporate identity can be taken in a similar spirit to restrictions of (PIIi) and (PIIii) with the following adaptions:

(B-PIIi) If a business $=$ a business then all competitorproperties (-attributes), administration level-properties (attributes), hierarchical structure-properties (-attributes), and regulator-properties (-attributes) of the former share all competitor-properties (-attributes), administration levelproperties (-attributes), hierarchical structure-properties (attributes), and regulator-properties (-attributes) of the latter.

(B-PIIii) If all competitor-properties (-attributes), administration level-properties (-attributes), hierarchical structure-properties (-attributes), and regulator-properties (attributes) of a business and all competitor-properties (attributes), administration level-properties (-attributes), hierarchical structure-properties (-attributes), and regulatorproperties (-attributes) of a business are shared then the former business $=$ the latter business.

(B-PIIi) and (B-PIIii) have the benefit of less generality than applications of (PIIi) and (PIIii) to businesses and (BPIIi) and (B-PIIii) are more informative; to establish the identity of a business, we just need to establish the competitor properties (attributes), administration level properties (attributes), hierarchical structure properties (attributes), and regulator properties (attributes).

We note that Peverelli's account of the identity of business here is applicable to Chinese business. At first look, the criteria also appears generalizable to all business, regardless of geographical location. There is, however, a counter-instance to this criteria. Take a business $b_{1}$ and a separate business $b_{2}$. Assume that $b_{1}$ and $b_{2}$ have the same competitors, same administration levels, same hierarchical structures, and the same government agencies that preside over them (and hence, they share the same relevant properties in these respects). $b_{1}$ and $b_{2}$ can have the same employees. Yet imagine that the work day of each employee is split in two; in the morning they work for business $b_{1}$ with a certain job description and in the afternoon they work for business $b_{2}$ with a different job description. The employees can work in the same location (or multiple locations if their business is carried out online). And part of their job descriptions is that the only other business that those employed by $b_{1}$ cannot act as competitors to are the employees working for $b_{2}$. And part of their job descriptions is that the only business that those employed by $b_{2}$ cannot act as competitors to are the employees of business $b_{1}$. Hence there are two separate businesses, even though all of Peverelli's criteria are fulfilled. 
What, then determines that business $b_{1}$ is distinct from business $b_{2}$ ? The job descriptions of the employees. Thus we claim that job descriptions of employees form part of the identity of business.

\section{The Relation between Business Identity and Value}

From the use of Floridi's criteria we can see how the identity of business is parasitic on business value. The more agents there are, the more instances of the provision relation there can be and so the greater the opportunity for business value. The more provision there is, the greater the opportunity for the distinction of businesses. Witness the creation of subsidiary companies - for example, Google and Alphabet - due to increases or potential increases in instances of the provision relation.

Bang, Cleemann, and Drucker [18] have revised Drucker's notion of business value purely in terms of the knowledge economy to encompass both the technical and social "as processes and as outputs of production" (p. 625). The pertinence they place on the consuming social subject can be extended to the identification of business value in the job descriptions of employees. Since job descriptions are designed to dictate the methods by which employees provide a good or service for consumption, the descriptions themselves play an important prescriptive role in such provision. Floridi's provision relation serves to capture these processes and outputs of production.

Production and consumption take a central role with regard to business value; any business with a loss in production losses value and a business with no production approaches worthlessness. A business with a loss of consumption of its goods or services results in a loss of business value. The job descriptions of employees - a means by which businesses can be identified - dictate the means by which production can be increased and as a result the accuracy of job descriptions are (in part) responsible for an increase in consumption. If job descriptions in a business are ill-defined then the means by which production can be increased is not sufficiently explicit for employees to carry out their roles in a maximally productive manner. Hence, the business value increase or loss that can result from job descriptions. Let us now conclude.

\section{v. Conclusion}

The implementation of Floridi's framework is a first step in a logical framework of business value. If we want to provide a quantization of value we could supplement the model by incorporating the values between 0 and 1 and ascribe them to instances of the provision relation, where 1 is maximal or optimal value, and 0 is minimal or worst value. But a successful realization of this is another project.

The value employees give to a business is mediated by their adherence to their job description which serves to define their role or duties within a business. In the knowledge economy, though, job descriptions are not without practical issues. The increased use of digitisation or virtualisation of business value and the increased demand for agility results in a tension. With more business agility comes the need of more flexibility in job descriptions. Yet job descriptions are rigid; any significant change to them requires re-hiring. So on one hand, there is a demand for increased flexibility in job descriptions in order to increase business value from the provision relation. And on the other hand, an employee requires rigidity in their job description if they are to engage in the provision of goods or services. This is a challenge business managers in the $21^{\text {st }}$ century knowledge economy currently face and will continue to face even more so in the future as digital or virtual business value increases.

\section{References}

[1] L. Floridi, The Ethics of Information, Oxford: Oxford University Press, 2013.

[2] M. E. Porter and M. R. Kramer, "Creating Shared Value," Business Harvard Review, vol. 89, pp.62-77, Jan/Feb 2011.

[3] G. Giraud and C. Renouard, "In search of an alternative to shareholder value maximization," Universite Paris1 PantheonSorbonne (Post-Print and Working Papers), 2011.

[4] R. E. Freeman, Strategic Management : A Stakeholder Apporach, Boston: Pitman, 1984.

[5] A. Lindgreen, "In Search of Relationship Quality, Customer Retention and Shareholder Value: Findings From an Exploratory, Qualitative Multiple Case Study," Journal on Chain and Network Science, vol. 1, pp. 49-63, 2008.

[6] K. T. Roberts, Assessin the Value of Relationship Quality in Comparison with SERVQUAL: A Scale Devleopmnt and Evnaluation, unpublished MA thesis, University of Auckland, Auckland, New Zealand, 1998.

[7] K. Roberts, S. Varki and R. Brokdie, "Measuring the quality of relationships in services: an empirical study," School of Business and Economics Working Papers Series, University of Auckland, Auckland, New Zealand, 2000.

[8] M. Porter, Competitive Advantage, New York: Free Press, 1985.

[9] R. Kordupleski, Mastering Customer Value Management: The Art and Science of Creating Competitive Advantage, Randolf, NJ: Customer Value Management, Inc., 2003.

[10] D. A. Ralston, D. J. Gustason, F. M. Cheung, and R. H. Terptra, "Differences in Mangerial Values: A Study of U.S., Hong Kong and PRC Managers," Journal of International Business Studies, vol. 24, pp.249-275, 1993.

[11] W. J. Bigoness and G. L. Blakely, "A Cross-National Study of Managerial Values," Journal of International Business Studies, vol. 27, pp. 739-748, 1996.

[12] K. E. Kristan Möller and P. Törrönen, "Business Suppliers' Value Creation Potential: A Capability Based Analysis," Industial Marketing Management, vol. 32, pp.109-18, 2003.

[13] E. Lesser and L. Prusak, "Creating Value with Knowledge: Insights from the IBM Institute for Business Value," New York: Oxford University Press, Inc., 2004.

[14] F. Wang and L. Vaughan, "Firm web Visibility and its Business Value", Internet Research, vol. 24, pp. 292-312, 2014.

[15] J. Weinman, Cloudonomis: the Business Value of Cloud Computing, Hoboken: Wiley, 2012.

[16] S. Titus, "Business Competitors and Business Advantage," Constatin Brancusi University of Targu Jiu Annals - Economy Series, vol. 4, pp. 225-228, 2013.

[17] P. Perrevelli, Chinese Corporate Identity, London: Routledge, 2006.

[18] Bang, Cleemann, and P. Drucker, "How to Create Business Value in the Knowledge Economy," Management Decision, vol. 48, pp. 616627, 2010.

About Author: Chrisopher Gifford is Jacobsen Tutor for the Royal Institute of Philosophy and Research Associate at the University of Bristol. 